\title{
PEMBERDAYAAN MASYARAKAT MELALUI PELATIHAN DAN PEMBENTUKAN KELOMPOK USAHA BERSAMA (KUB) PETERNAKAN AYAM DI DESA TATELU, KECAMATAN DIMEMBE, KABUPATEN MINAHASA UTARA
}

\author{
Alzefin Y. R. M. Sinolungan * \\ Universitas Negeri Manado \\ alzefinsinolungan@unima.ac.id \\ Olivia J. Lalamentik \\ Universitas Negeri Manado \\ olivialalamentik@unima.ac.id
}

\begin{abstract}
Abstrak
Desa Tatelu Rondor merupakan desa hasil pemekaran wilayah dari desa Tatelu Induk yang sangat luas wilayahnya memiliki mata pencaharian sebagai petani dan perikanan ikan mas dan mujair dan peternakan ayam, babi, bebek dan penambangan emas. Usaha masyarakat desa Tatelu Rondor dibidang pertanian, perikanan dan peternakan dan penambangan emas seringkali tidak maksimal memberikan pendapatan bagi masyarakat setempat menyebabkan kendala dengan keterbatasan sarana produksi pertanian dan lahan pertanian, perikanan, peternakan dan penambangan emas yang sebagian besar sudah dijual pada pihak lain. Mata pencaharian bersumber pada ekonomi pertanian, perikanan belum banyak memberikan kontribusi bagi pendapatan ekonomi masyarakat. Situasi ini menjadi sulit akibat minimnya alternatif mata pencaharian lain sebagai alternatif pendapatan masyarakat desa Tatelu Rondor.

Solusi program mengatasi kondisi ekonomi yang sulit ini ditawarkan melalui Program Kemitraan Masyarakat (PKM) yang difasilitasi oleh Lembaga Penelitian dan Pengabdian Kepada Masyarakat Universitas Negeri Manado dengan memberikan alternatif mata pencaharian lainnya yaitu beternak unggas (ayam) secara berkelompok dengan membentuk Kelompok Usaha Bersama (KUB) sebagai solusi alternatif mata pencaharian berkelanjutan dengan Skema Program Pemberdayaan Ekonomi Masyarakat melalui Pelatihan Usaha Peternakan Ayam dan Pembentukan Kelompok Usaha Bersama Tatelu Rondor Peternakan Ayam.

Luaran yang diharapkan melalui program ini adalah peningkatan kapasitas dan kapabilitas masyarakat dalam pengelolaan usaha peternakan ayam, adanya literasi ekonomi masyarakat dalam usaha produktif beternak ayam dan terbentuknya Kelompok Usaha Bersama (KUB) Peternak Ayam di Desa Tatelu Rondor, Kecamatan Dimembe, Kabupaten Minahasa Utara.

Kata Kunci: Pemberdayaan Ekonomi Masyarakat, Beternak Ayam, Alternatif Mata Pencaharian, Pembentukan KUB di Desa Tatelu Rondor.
\end{abstract}




\section{PENDAHULUAN}

\subsection{Analisis Situasi}

Desa Tatelu Rondor berada di Kecamatan Dimembe, Kabupaten Minahasa Utara. Usaha masyarakat Desa Tatelu Rondor adalah bidang pertanian, perkebunan, perikanan, pertambangan emas, peternakan sapi, babi, ayam seringkali tidak maksimal memberikan pendapatan bagi masyarakat karena terkendala dengan keterbatasan sarana produksi pertanian, perkebunan, perikanan, pertambangan emas, peternakan sapi, babi, ayam serta membutuhkan alternatif mata pencaharian yang berkelanjutan untuk meningkatkan akan pendapatan ekonomimnya. Kondisi yang ada di desa Tatelu Rondor, Kecamatan Dimembe, Kabupaten Minahasa Utara, Propinsi Sulawesi Utara memiliki potensi sumber daya alam yang melimpah seperti potensi tanaman perkebunan yaitu jagung, ketela pohon tanaman padi dan perikanan ikan mas dan ikan mujair dan tanaman padi yang dapat diolah menjadi pakan ternak seperti ayam dan jenis ungags lainnya. Desa Tatelu Rondor ini memiliki potensi hasil pertambangan emas dan potensi hasil usahan ternak yaitu ayam, babi dan jenis petenakan lainnya, karena bahan baku pakan ternak telah tersedia di desa Tatelu Rondor, Kecamatan Dimembe, Kabupaten Minahasa Utara, Propinsi Sulawesi Utara.

\subsection{Permasalahan Mitra}

Masyarakat desa Tatelu Rondor, Kecamatan Dimembe, Kabupaten Minahasa Utara masih bergantung pada mata pencaharian seperti bertani,berkebun, dibidang perikanan ikan mujair, ikan mas, dan penambangan emas dan mengolah lahan pertanian, perkebunan, perikanan, penambangan, peternakan dan belum banyak melakukan diversifikasi mata pencaharian lainnya sehingga saat hasil pertanian tidak memberikan hasil yang maksimal dalam meningkatkan pendapatan, masyarakat tidak memiliki alternatif mata pencaharian lainnya. Masalah lainnya yang terjadi di Desa Tatelu Rondor,Kecamatan Dimembe,Kabupaten Minahasa Utara adalah belum maksimalnya masysrakat memanfaatkan potensi ekonomi yang lainnya,seperti: potensi beternak ungags atau ayam yang dimiliki banyak di desa. Bahan baku seperti: jagung,bekatul atau limbah padi tersedia cukup melimpah. Bahan baku tersebut dapat diolah menjadi pakan ternak. Masyarakat desa Tatelu Rondor belum memiliki kesadaran yang tinggi dalam membentuk kelompokkelompok usaha produktif, seperti: Kelompok Usaha Bersama (KUB) di bidang pertanian dan peternakan ayam dan perikanan ikan mujair dan ikan mas, penambangan emas.

\section{SOLUSI DAN TARGET LUARAN}




\subsection{Solusi Permasalahan}

Program Kemitraan yang ada dilakukan oleh pengusul program yang difasilitasi oleh Lembaga Penelitian dan Pengabdian pada Masyarakat memiliki target yaitu:

1.Adanya alternatif mata pencaharian yang berkelanjutan bagi masyarakat desa Tatelu Rondor,

Kecamatan Dimembe, Kabupaten Minahasa Utara, Propinsi Sulawesi Utara.

2.Adanya peningkatan literasi ekonomi masyarakat desa Tatelu Rondor, Kecamatan Dimembe,

Kabupaten Minahasa Utara, Propinsi Sulawesi Utara pada aktivitas ekonomi produktif yang

memberikan pendapatan yang baik bagi pihak masyarakatnya.

3.Adanya literasi dalam Pengelolaan Usaha, Manajemen Usaha Peternakan Ayam Skala Kecil.

4.Adanya peningkatan Kualitas Hidup masyarakat melalui Pemberdayaan

Ekonomi Masyarakat pada

usaha peternakan ayam skala kecil.

5.Adanya Kelompok Usaha Bersama (KUB) di bidang Peternakan Unggas (Ayam)yang terbentuk.

\subsection{Target Luaran}

Untuk Luaran Program Kemitraan dengan Masyarakat Desa Tatelu Rondor, Kecamatan Dimembe, Kabupaten Minahasa Utara, Propinsi Sulawesi Utara adalah

\begin{tabular}{|c|c|c|}
\hline Nomor & Jenis Luaran & $\begin{array}{l}\text { Indikator } \\
\text { Capaian }\end{array}$ \\
\hline 1. & $\begin{array}{l}\text { Publikasi Ilmiah } \\
\text { Artikel,Jurnal } \\
\text { /Prosiding }\end{array}$ & $\begin{array}{l}\text { Draft } \\
\text { Publikasi }\end{array}$ \\
\hline 2. & $\begin{array}{l}\text { Publikasi Media Massa } \\
\text { (Cetak /Elektronik) }\end{array}$ & Ada \\
\hline 3. & $\begin{array}{l}\text { Peningkatan Literasi } \\
\text { Masyarakat Pada Usaha } \\
\text { Peternakan Ayam }\end{array}$ & Ada \\
\hline 4. & $\begin{array}{l}\text { Tersedianya Alternatif } \\
\text { Mata Pencaharian } \\
\text { Berkelanjutan Bagi } \\
\text { Masyarakat Desa Tatelu } \\
\text { Rondor,Kecamatan } \\
\text { Dimembe,Kabupaten } \\
\text { Minahasa } \\
\text { Utara,Propinsi Sulawesi } \\
\text { Utara sebagai Mitra } \\
\text { Program Kemitraan } \\
\text { Masyarakat (PKM) }\end{array}$ & Ada \\
\hline 5. & $\begin{array}{ll}\text { Terbentuknya } & \\
\text { Kelompok } & \text { Usaha } \\
\text { Bersama } & \text { (KUB) } \\
\text { Peternak Ayam } & \end{array}$ & Ada \\
\hline 6. & Buku Yang Ber-ISBN & Tidak Ada \\
\hline
\end{tabular}

\section{METODE PELAKSANAAN}

\subsection{Metode Solusi Permasalahan}

Metode pelaksanaan kegiatan Program Kemitraan Masyarakat (PKM) ini dilaksanakan dengan cara Pelatihan dan Bimbingan Teknis berupa: Analisis Usaha Peternakan Ayam, cara beternak ayam, 
manajemen produksi dan pemasaran hasil ternak ayam dan Pembentukan Kelompok KUB Beternak Ayam.

\subsection{Gambaran Proses}

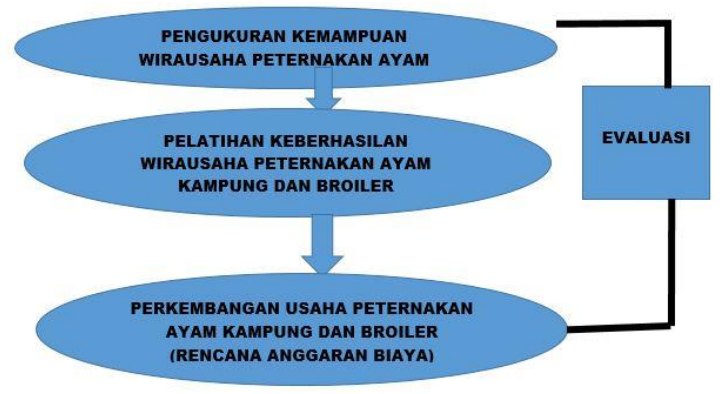

TAHAPAN PELAKSANAAN (A).SOSIALISASI PETERNAKAN AYAM

(B).DISKUSI ANALISIS KEBUTUHAN MASYARAKAT BERSAMA STAKEHOLDER

(C).PELATIHAN ANALISIS USAHA PETERNAKAN

AYAM KAMPUNG DAN BIASA/BROILER

(D).PELATIHAN CARA BETERNAK AYAM

(E).PELATIHAN PEMASARAN HASIL TERNAK AYAM

(F).PELATIHAN PEMBENTUKAN

KELOMPOK USAHA BERSAMA

(KUBE)PETERNAKAN AYAM

KAMPUNG DAN BIASA/ BROILER

Tahapan Pelaksanaan Peternakan Ayam Kampung dan Ayam Biasa /Broiler"

a.Tahap Sosialisasi Peternakan Ayam Kampung dan Ayam Biasa/ Broiler

Tahapan Sosialisasi dilakukan oleh Pengusul Program bekerja sama dengan Lembaga Penelitian dan Pengabdian Kepada Masyarakat, Universitas Negeri Manado di fasilitasi oleh pihak Pemerintah Desa Tatelu Rondor, Kecamatan Dimembe, Kabupaten
Minahasa Utara, Propinsi Sulawesi Utara dimana Tahapan Sosialisasi ini dilakukan dalam rangka menyamakan persepsi serta pemikiran mengenai arti pentinga program kemitraan ini dengan masyarakat serta pihak Kampus Universitas Negeri Manado dalam hal ini Lembaga Penelitian dan Pengabdian Kepada Masyarakat, Universitas Negeri Manado.

\section{b.Tahap Diskusi Analisis Kebutuhan}

\section{Masyarakat Bersama Stakeholder}

Tahapan diskusi analisis kebutuhan ini dilibatkan seluruh Stakeholder Program Kemitraan yaitu Perwakilan Masyarakat, Pemerintah Desa Tatelu Rondor, Kecamatan Dimembe, Kabupaten Minahasa Utara, Propinsi Sulawesi Utara, pihak LPPM Universitas Negeri Manado dan Tim Pengusul Program Kemitraan ini. Diskusi dilaksanakan bertujuan untuk mengidentifikasi permasalahan serta sumberdaya yang dimiliki oleh masyarakat dan wilayah desa Tatelu Rondor, Kecamatan Dimembe, untuk dijadikan sebagai bahan informasi dalam menunjang Program Pemberdayaan Ekonomi Masyarakat melalui Usaha Peternakan Ayam berskala kecil melalui kegiatan PKM.

(1).Tahapan Pelatihan Analisis Usaha Peternakan Ayam Kampung dan Broiler

Pada tahapan ini dilakukan Pelatihan Teknis serta Penyuluhan mengenai Penyusunan Analisis Usaha Peternakan Ayam berskala kecil. 
Diharapkan melalui adanya Pelatihan Analisis Usaha Skala Kecil ini masyarakat mitra memiliki literasi dalam menyusun analisis usaha sehingga dapat memaksimalkan pada pendapatan dari hasil beternak ayam berskala kecil. Contoh analisis usaha dibuat oleh Tim Pengusul.

(2).Tahapan Pelatihan Cara Beternak Ayam Kampung dan Biasa/Broiler

Tahapan ini adalah Pelatihan Teknis Bagaimana Beternak Ayam yang benar. Dimana pelatihan teknis ini dibantu oleh Tenaga Teknis atau ahli yang berpengalaman dalam usaha peternakan ayam skala kecil maupun skala besar, dengan menggunakan dokter hewan dan menggunakan vaksinasi peternakan ayam, dan memperhatikan tingkat kebersihaan ayam, tingkat pakan peternakan ayam, tingkat pemeliharaan ayam dalam hal ini mengenai air bersih, tingkat keamanan peternakan ayam:kandang peternakan ayam yang representatif serta modal peternakan ayam.

\section{(3).Tahapan Pelatihan Pemasaran Hasil}

\section{Ternak Ayam Kampung dan Broiler}

Tahapan akhir pelatihan pemasaran hasil ternak ayam adalah memberikan pemahaman serta literasi pada masyarakat di desa Tatelu Rondor, Kecamatan Dimembe, Kabupaten Minahasa Utara,Propinsi Sulawesi Utara mengenai bagaimana bentuk pemasaraan hasil ternak ayam yang dapat menguntungkan peternakan skala kecil. Dimana pelatihan ini diberikan oleh Tim Pengusul Program PKM/Program Kemitraan Masyarakat ini dengan dibantu oleh beberapa akademisi yang ahli dalam hal bidang pemasaran/marketing baik dalam jangkauan kecil, menengah dan besar seperti melalui pasar tradisional, pasar supermarket, melalui online bidang marketing/ pemasaran.

c.Tahapan Pelatihan Pembentukan Kelompok Usaha Bersama (KUB)

\section{Peternakan Ayam}

\section{Kampung dan Ayam Biasa / Broiler}

Tahapan ini adalah Tahapan Pelatihan bagi masyarakat berupa: Bimbingan Teknis Pembentukan Kelompok Usaha Bersama (KUB). Pembentukan Kelompok Usaha Bersama (KUB) ini mengacu pada Tahapan Pembentukan Kelompok KUB dengan melibatkan Pemerintahan Desa Tatelu Rondor, Kecamatan Dimembe, Kabupaten Minahasa Utara, Propinsi Sulawesi Utara.

\section{HASIL DAN LUARAN YANG DICAPAI}

\section{A.Hasil Pelaksanaan Kegiatan}

Setelah kegiatan pelatihan dilaksanakan dengan Metode Ceramah, Diskusi, Simulasi,maka hasilnya adalah:

(1).Seluruh peserta baik pihak pemerintah dan para anggota kelompok usaha bersama (KUBE) Tatelu Rondor Kelompok Peternakan Ayam Kampung dan Ayam Biasa/ Broiler, Desa Tatelu Rondor, 
Kecamatan Dimembe, Kabupaten Minahasa Utara, Propinsi Sulawesi Utara boleh memahami tentang pentingnya kewirausahaan dalam berbisnis dan pada akhirnya mempunyai mindset/ pola pikir kewirausahaan.

(2).Seluruh peserta sudah mampu menyusun Rencana Bisnis (Rencana Anggaran Biaya/RAB), mulai dari Perencanaan Pengadaan Bibit Ayam Kampung dan Ayam Broiler, Pakan Ternak, Kandang Ternak, Modal Biaya Anggaran Peternakan Ayam,Pemasaran Peternakan Ayam, Penetapan Harga Ayam, Pekerja Ayam Peternakan, Pemilihan Lokasi dan Cara Memilih Promosi Yang Efektif melalui Media Sosial (Online).

\section{B. Pembahasan}

\section{(1).Pemahaman Peserta tentang}

\section{Kewirausahaan}

Sebelum kegiatan pelatihan dilaksanakan, pemahaman tentang peserta tentang kewirausahaan sangat beraneka ragam, pengetahuan mereka bervariasi, ada yang sudah memahami, tapi masih sedikit, ada pula yang justru tidak mengetahui tentang apa sebenarnya mengenai kewirausahaan. Hal ini muncul saat dilakukan pre-test yang dilakukan sebelum dilakukan bimbingan dan pelatihan, ini terjadi sebab bervariasinya tingkat pendidikan. Umumnya peserta peternakan ayam kampung dan ayam biasa/broiler yang mempunyai peternakan masing-masing adalah ibu rumah tangga dan bapak yang mempunyai latar belakang pendidikan formal dibawah tingkat SMA, tapi ada beberapa peserta yang sudah pernah mengikuti pelatihan kewirausahaan/ pemasaran, baik dilingkungan gereja, desa maupun instansi lainnya.

Setelah kegiatan pembinaaan dan pelatihan selesai dilaksanakan, maka para peserta yaitu para peternakan ayam kampung dan ayam biasa/broiler kelompok usaha bersama (KUBE), pada umumnya sudah memahami tentang kewirausahan yaitu mengenai pengertian kewirusahaan, sifat dan karakter

wirusaha membedakan usaha sesungguhnya dan usaha spekulatif, berani mengambil resiko, mampu berpikir kreatif, akhirnya mampu menumbuhkan pola pikir sebagai wirausaha /pebisnis bagi para peserta, membuktikan bahwa adanya test proses terlihat dari hasil diskusi dan simulasi membuat bisnis secara utuh, mulai dari pengadaan barang peternakan ayam kampung dan ayam biasa/broiler, penetapan harga, pemilihan tempat usaha (pemasaran)melalui mulut ke mulut atau media sosial atau online, dan bagimana strategi promosi yang efektif agar peternakan ayam tidak berbahaya mengenai penyakit flu burung, tapi rusak telur ayam, tapi tidak terjual.

Selanjutnya dilakukan post test atau tes akhir, dimana sebagian besar peserta yaitu $85 \%$ sudah memberikan jawaban yang benar dan tepat atas seluruh pertanyaan 
yang diajukan, sedangkan $15 \%$ masih memberikan jawaban yang kurang tepat. Oleh karena itu, adanya pemahaman dan kemampuan berbeda tentang kewirausahaan, disebabkan oleh latar belakang pendidikan dan pengalaman yang berbeda-beda.

\section{2).Keterampilan Peserta Membuat}

\section{Strategi Pemasaran Peternakan Ayam}

Sebelum pelatihan dibuat, maka umumnya peserta belum mempunyai pola pikir mengenai kewirausahaan, belum tahu mengenai bagaimana mengolah bisnis dengan membuat satu perencanaan yang disebut Strategi Pemasaran secara baik dan benar, sehingga mereka tidak mampu memprediksi berapa jumlah produk yang harus disiapkan atau berapa persediaan barang yang tepat, bagaimana strategi penetapan harga, pemilihan lokasi peternakan ayam, tempat pemasaran peternakan ayam, berapa persediaan barang yang tepat, mempromosikan peternakan ayam agar laris manis, namun setelah dilakukan pembianaan dan pelatihan, maka umumnya peserta yaitu 85 $\%$ sudah mampu melakukan rencana strategi pemasaran secara lengkap, hal ini disebabkan karena besar kemauan para peserta. Para peserta menyambut baik kegiatan ini, hal ini muncul keseriusan sehingga mereka mengikuti kegiatan secara tuntas dan memberikan apresiasi yang tinggi pada kegiatan pelatihan, maka muncul saat pemateri memberikan materi, diskusi dan Tanya jawab dan simulasi.

\section{RENCANA TAHAPAN BERIKUTNYA}

Enterpreneurship / wirausaha peternakan ayam adalah orang yang merasa hidupnya kurang nyaman, terancam, miskin atau kurang bermakna. Seorang wirausaha berjuahg mengejar kenyamanan baru, bisa bergerak, berjalan, berpikir, mengetuk pintu, mengambil resiko, mencari produk, membuat membangun usaha dan mendatangi para pelangga peternakan ayam.

Dalam kegiatan wirausaha terdapat beberapa kekurangan atau kelemahan dalam kegiatan ini,yaitu:

(1).Mitra dalam hal ini kelompok usaha bersama (Kube) Peternakan Ayam Kampung dan Biasa/Broiler sudah tidak aktif sehingga untuk mempertemukan anggota kelompok agak sulit.

(2).Adanya kepeduliaan dari Kepala Desa Tatelu Rondor, Kecamatan Dimembe, Kabupaten Minahasa Utara, Propinsi Sulawesi Utara membuat anggota kelompok bersemangat hadir dalam pelatihan, mendorong Ketua Pelaksana untuk melakukan pengabdian kembali.

(3).Kelemahan/keterbatasan lainnya adalah para peserta anggota kelompok usaha bersama (Kuba) Peternakan Ayam Kampung dan Biasa/Broiler umumnya sebagai pemilik peternakan ayam dan

Penjaga peternakan ayam sehingga agak sulit untuk memberikan pelatihan dalam 1 
ruangan atau Gedung yang jauh dari lokasi peternakan ayam dan pemasarannya.

(4).Peserta hanya 10 peserta yang aktif yang lain tidak biasa meninggalkan lokasi pemasaran peternakan Ayam,seperti di pasar tradisional sesuai jadwal pasar harian setempat.Kegiatan pelatihan penciptaan pola pikir kewirausahaan harus dilakukan terus menerus dan tidak bisas terputus, karena perlu adanya kegiatan yang berkelanjutan sebagai berikut:

(1).Adanya kemitraan yang berkelanjutan dengan mitra utama yang sama, bila perlu menambah mitra lainnya yang mempunyai relasi usaha produk turunan peternakan ayam seperti: peternakan ayam

dipasarkan di tempat Kentucky Fried Chicken, Mc Donald, Texas, rumah makan, kios rumah makan, pasar tradisional, pasar modern/ supermarket, dan lain sebagainya. (2).Kemitraan ini adalah langkah awal untuk membuka kerjasama selanjutnya dengan pemerintah Kabupaten Mitra setempat dan ekspansi keluar dari propinsi Sulawesi Utara, baik dalam negeri dan luar negeri.

(3).Perlu adanya kesinambungan kegiatan setiap tahun dengan bantuan dana dari LPPM dan lembaga Dinas Pertanian dan Peternakan Propinsi Sulawesi Utara agar usaha anggota mitra Kelompok Usaha

Bersama (Kube) Peternakan Ayam Kampung dan Biasa/ Broiler agar usaha anggota mitranya menjadi semakin berkembang dalam manajemen dan pemasaran dan keuangan serta kesejahteraan- kesejahteraan keluarganya masing -masing kepada masyarakat Desa Tatelu Rondor, Kecamatan Dimembe, Kabupaten Minahasa Utara, Propinsi Sulawesi Utara.

\section{KESIMPULAN DAN SARAN}

\section{A.KESIMPULAN}

(1). Setelah mengikuti pembinaan dan pelatihan peternakan ayam kampung dan ayam biasa/broiler, aka seluruh mitra kelompok usaha bersama (Kube) di desa Tatelu Rondor, Kecamatan Dimembe, Kabupaten Minahasa Utara, Propinsi Sulawesi Utara tentang penciptaan pola pikir kewirausahaan menunjukkan bahwa sebagaian besasr peserta sudah memahami pentinnya dalam dunia usahanya.

(2).Mengikuti pelatihan, maka keterampilan para anggota kelompok mitra usaha bersama (Kube) mitra Pemilik peternakan ayam kampung dan biasa/broiler di desa Tatelu Rondor, Kecamatan Dimembe,

Kabupaten Minahasa Utara, Propinsi Sulawesi Utara sudah mampu menjadi wirausaha mandiri, sebab sudah mampu membuat rencana usaha secara utuh sebagai pedoman, dimana dapat dipraktek

kan dalam pelaksanaannya, agar berikut akan sukses dalam berbisnis dan pendapatan serta kesejahteraan keluarganya masing-masing meningkat dan bermanfaat hari depan. 
(3).Terdapat perbedaaan persepsi mengenai kewirausahaan dan perbesaan latar belakang pendidikan dan Pengalaman di dunia bisnis sehingga dapat menjadikan kendala utama dalam memulai pelatihan, tapi peserta pelatihan serius dalam mengikuti pelatihan, sehingga akhirnya pelatihan ini boleh dikata sukses atau berhasil dengan memuaskan.

\section{B.SARAN}

(1).Kegiatan pelatihan menciptakan pola pikir kewirausahaan perlu dilakukan secara berkesinambung kemudian diperlukan dukungan dari berbagai pihak termasuk Lembaga Pengabdian Masyarakat Universitas Negeri Manado sekiranya terus mencetuskan program yang menyentuh masyarakat dengan memberikan bantuan dana yang sesuai.(2).Pemerintah maupun pihak -pihak yang terkait perlu merespons kegiatan yang dilakukan oleh LPPM- Universitas Negeri Manado dengan menyiapkan sarana dan prasarana yang memadai.

(3).Para anggota mitra Desa Tatelu Rondor, Kecamatan Dimembe, Kabupaten Minahasa Utara, Propinsi Sulawesi Utara Peternakan Ayam Kampung dan Biasa/ Broiler hendaknya selalu meningkatkan pengetahuan tentang peranan kewirausahaan dengan mengikuti pelatihan-pelatihan yang dilakukan oleh lembaga LPPM UNIMA dan Dinas Pertanian dan Peternakan Propinsi Sulawesi Utara maupun melalui media sosial online agar supaya usaha / bisnis semakin meningkat dan berkembang dalam segala hal wirausaha.

\section{KEPUSTAKAAN}

Arsyad, S. 2006. Konservasi Tanah dan Air. IPB Press, Bogor.

Badan Pusat Statistik. 2017. Kecamatan Airmadidi Dalam Angka Tahun 2017. Minahasa Utara.

Bintarto,,R. 1977. Pengantar Geografi Kota.Yogyakarta : Spring.

Direktorat Jenderal Penataan Ruang. Pedoman Kriteria Teknis Kawasan Budi Daya:Departemen

Pekerjaan Umum, Desember 2008. Kabupaten Minahasa Utara.

Peraturan Daerah Kabupaten Minahasa Utara Nomor 01 Tahun 2013 Tentang Jurnal Spasial Vol 5. No. 2, 2018 ISSN 2442 3262170 Program Studi Perencanaan Wilayah dan Kota

Rencana Tata Ruang Wilayah Kabupaten Minahasa Utara Tahun 2013-2033. Airmadidi.

Moh. Nazir, Ph.D.1983. Metode Penelitian. PT. Ghalia Indonesia.

Muta'ali, Lutfi. 2012. Daya Dukung Lingkungan Untuk Perencanaan Pengembangan Wilayah. Yogyakarta : Penerbit Badan Penerbit Buku Geografi (BPBG) Universitas Gadjah Mada. Republik Indonesia. 2011. Undang-Undang Nomor 1 tentang Perumahan dan Kawasan Permukiman. Jakarta: Sekretariat Negara. Sadana, Agus. 2014.

Perencanaan Kawasan Permukiman. Yogyakarta : Graha Ilmu.

Anita, Widagdo W. 2011. Budidaya Ayam Broiler 28 Hari Panen. Yogyakarta:Pinang Merah. 
Aziz FA. 2009. Analisis Risiko dalam Usahaternak Ayam Broiler (Studi Kasus Usaha

Peternakan X di Desa Tapos, Kecamatan Tenjo, Kabupaten Bogor)[Skripsi]. Bogor: Fakultas Ekonomi dan Manajemen Institut Pertanian Bogor.

[BMKG] Badan Meteorologi, Klimatologi, dan Geofisika. 2012. Rata-rata Unsur Iklim Kota Palembang. http://iklim.bmg.go.id/index.jsp [3 Juni 2012].

[BPS] Badan Pusat Statistik. 2010. Produk Domestik Bruto per Kapita per Tahun. Produk Nasional Bruto per Kapita dan Pendapatan Nasional per Kapita Tahun 2000 - 2009.

http://www.bps.go.id [30 Oktober 2011].
[BPS] Badan Pusat Statistik. 2012. Produk Domestik Bruto Atas dasar HargaBerlaku Menurut Lapangan Usaha Tahun 2004 2011.

http://bps.go.id/tab_sub/view.php?tabel=1 \&daftar=1\&id_subyek=11\&notab=1 [13 April 2012].

[BPS] Badan Pusat Statistik Provinsi Sumatera Selatan. 2010. Berita Resmi Statistik

Pertumbuhan Ekonomi Sumatera Selatan Triwulan III 2011. http://sumsel.bps.go.id//index.php?option $=$ com content\&task=view\&id=1 89\&Itemid=122.pdf [13 April 2011]. [BPS] Badan Pusat Statistik Provinsi Sumatera Selatan. 2011a. Provinsi Sumatera Selatan dalam Angka 2011. Palembang: Badan Pusat Statistik. 